Article type: audit report

Corresponding author information: Dr Hannah M Rickman, Mortimer Market Centre, London, UK. Email: hannahrickman1@gmail.com

\title{
Missed opportunities for tuberculosis prevention among patients accessing a UK HIV service
}

\author{
Hannah M Rickman ${ }^{1}$, Robert F Miller ${ }^{1,2,3,4}$, Stephen Morris- \\ Jones $^{3,5}$, Lusha Kellgren ${ }^{3}$, Simon G Edwards ${ }^{1}$, Alison D Grant ${ }^{1,2,6,7}$
}

${ }^{1}$ Bloomsbury Clinic, Mortimer Market Centre, Central \& North West London NHS Foundation Trust, London, UK

${ }^{2}$ TB Centre, London School of Hygiene \& Tropical Medicine, London, UK ${ }^{3}$ TB Service, North Central London South Hub, Whittington Hospital, London, UK ${ }^{4}$ Institute for Global Health, University College London, London, UK

${ }^{5}$ Clinical Microbiology Department, University College London Hospitals NHS Foundation Trust, London, UK

${ }^{6}$ Africa Health Research Institute, School of Nursing and Public Health, University of KwaZulu-Natal, South Africa

${ }^{7}$ School of Public Health, University of the Witwatersrand, South Africa 


\begin{abstract}
Objectives: United Kingdom guidelines recommend screening for and treatment of latent tuberculosis infection (LTBI) in HIV-positive patients at high risk of active tuberculosis disease (TB), but implementation is sub-optimal. We investigated potential missed opportunities to identify and treat LTBI among HIV-positive patients accessing a large HIV outpatient service in London.
\end{abstract}

Methods: Case records of all adult patients attending our service for HIV care diagnosed with active TB between 2011 and 2015 were reviewed, to determine whether they met criteria for LTBI screening and whether screening was undertaken.

Results: Twenty-five patients were treated for TB. Of 15 (60\%) patients who started TB treatment $\geq$ six months after HIV diagnosis, 14 (93\%) met UK guideline-recommended criteria for LTBI screening and treatment; only one (7\%) had been screened for LTBI. Eight of these 15 (53\%) patients had additional risk factors for TB which are not reflected in current UK guidelines.

Conclusions: Of 15 patients treated for TB $\geq$ six months after diagnosis of HIV, 14 (93\%) had not been screened for LTBI, suggesting missed opportunities for TB prevention. People living with HIV may benefit from a broader approach to LTBI screening which takes into account additional recognised TB risk factors and ongoing TB exposure.

\title{
Keywords
}

HIV infection, tuberculosis, latent tuberculosis, tuberculosis/prevention \& control, preventive therapy, interferon-gamma release assays 


\section{Background}

People living with HIV are at high risk of developing active tuberculosis (TB) ${ }^{1}$. Screening for and treatment of latent TB infection (LTBI) in selected HIV patients is effective and cost-effective ${ }^{2,3}$ and is recommended by the British HIV Association (BHIVA) for patients at high risk of TB reactivation, defined by CD4 count, duration of antiretroviral therapy (ART) and TB incidence of their region of origin ${ }^{4}$ (Table 1). However, a recent evaluation found that only $57.4 \%$ of UK geographical areas offer screening ${ }^{5}$.

Table 1. Summary of British HIV Association 2011 guidelines for screening and treatment of latent tuberculosis infection in HIV-infected persons ${ }^{4}$

\begin{tabular}{|c|c|c|}
\hline $\begin{array}{l}\text { Tuberculosis prevalence of region of } \\
\text { origin* }\end{array}$ & $\begin{array}{l}\text { Criteria for latent tuberculosis screening } \\
\text { according to British HIV Association } \\
\text { guidelines }\end{array}$ & $\begin{array}{l}\text { Recommendation if } \\
\text { criteria are met }\end{array}$ \\
\hline $\begin{array}{l}\text { Low (including UK, Western Europe, } \\
\text { Australia, USA, Canada and New Zealand) }\end{array}$ & $\begin{array}{l}\text { On ART for less than } 6 \text { months and } \\
\text { CD } 4<350\end{array}$ & \multirow{3}{*}{$\begin{array}{l}\text { Screen for latent } \\
\text { tuberculosis infection } \\
\text { using interferon- } \\
\text { gamma release assay } \\
\text { and provide chemo- } \\
\text { preventative therapy if } \\
\text { positive }\end{array}$} \\
\hline $\begin{array}{l}\text { Medium (including Eastern Europe, } \\
\text { Central Asia, North Africa and the Middle } \\
\text { East, South Asia, East Asia and the } \\
\text { Caribbean) }\end{array}$ & On ART for less than 2 years and $C D 4<500$ & \\
\hline High (sub-Saharan Africa) & On ART for less than 2 years & \\
\hline
\end{tabular}

ART: antiretroviral therapy; UK: United Kingdom; USA: United States of America

*Numerical definitions of "low" / "medium" / "high" incidence not included in the guidelines

In our UK HIV clinic, 33\% of patients originate from high- or medium-TB incidence regions. We introduced a policy of LTBI screening and treatment according to BHIVA guidelines in 2011, but an audit in 2015 revealed only $12.1 \%$ screening completion ${ }^{6}$. We retrospectively reviewed case notes of HIV patients diagnosed with $T B$, to investigate whether there were missed opportunities to identify and treat LTBI.

\section{Methods}

Adults ( $\geq 18$ years) attending our service for HIV care and diagnosed with TB in 20112015 were included. TB cases were identified from the Public Health England London TB Register and from our microbiology service's database. Patients were classified into two groups according to the time between HIV diagnosis and TB treatment start date: 
"early" (less than six months), or "late" (six months or more), assuming that TB episodes starting less than six months after HIV diagnosis probably could not have been averted by screening and treatment of LTBI. We compared our clinic practice with 2011 BHIVA guidance ${ }^{4}$.

\section{Results}

We identified 25 patients diagnosed with TB between 2011 and 2015 (Table 2). Twelve (48\%) were from high-, four (16\%) from medium-, and nine (36\%) from low-TB incidence regions of origin. Time between HIV diagnosis and TB treatment start date ranged from 5 days to 27 years. Ten (40\%) had TB "early" (less than six months after HIV diagnosis).

Table 2. Characteristics of HIV-positive individuals with tuberculosis

\begin{tabular}{|c|c|c|c|c|}
\hline \multicolumn{3}{|l|}{ Group } & Early & Late \\
\hline \multicolumn{3}{|c|}{ Time between HIV diagnosis and TB episode } & $<6$ months $(\mathrm{N}=10)$ & $\geq 6$ months $(\mathrm{N}=15)$ \\
\hline \multicolumn{3}{|c|}{ Time between HIV diagnosis and TB episode, median (range) } & $\begin{array}{l}10.5 \text { days } \\
\text { (-5-125 days) }\end{array}$ & $\begin{array}{l}4.6 \text { years } \\
(1.1-26.9 \text { years })\end{array}$ \\
\hline \multicolumn{3}{|l|}{ Male, $\mathrm{n}(\%)$} & $5(50 \%)$ & $10(67 \%)$ \\
\hline \multicolumn{3}{|c|}{ Age (years), median (range) } & $47(24-56)$ & $42(29-59)$ \\
\hline \multirow{11}{*}{$\begin{array}{l}\text { Risk } \\
\text { factors for } \\
\text { TB } \\
\text { infection }\end{array}$} & \multirow{3}{*}{$\begin{array}{l}\text { Region of } \\
\text { origin* }\end{array}$} & Low TB incidence & $2(20 \%)$ & $7(47 \%)$ \\
\hline & & Medium TB incidence & $2(20 \%)$ & $2(13 \%)$ \\
\hline & & High TB incidence & $6(60 \%)$ & $6(40 \%)$ \\
\hline & \multirow{7}{*}{$\begin{array}{l}\text { Other TB } \\
\text { risk } \\
\text { factors }\end{array}$} & $\begin{array}{l}\text { Extensive travel/residence in high- } \\
\text { incidence area }\end{array}$ & $1(10 \%)$ & $2(13 \%)$ \\
\hline & & TB contact & $0(0 \%)$ & $3(20 \%)$ \\
\hline & & Healthcare worker & $1(10 \%)$ & $2(13 \%)$ \\
\hline & & Intravenous drug use & $0(0 \%)$ & $2(13 \%)$ \\
\hline & & Previous/current prison resident & $0(0 \%)$ & $2(13 \%)$ \\
\hline & & Homelessness & $1(10 \%)$ & $1(7 \%)$ \\
\hline & & $\begin{array}{l}\text { At least one of these "other" risk } \\
\text { factors }\end{array}$ & $3(30 \%)$ & $8(53 \%)$ \\
\hline & \multicolumn{2}{|c|}{ At least one of these risk factors for TB infection ${ }^{+}$} & $9(90 \%)$ & $12(80 \%)$ \\
\hline \multicolumn{3}{|c|}{ CD4 cell count at start of TB episode (cells $/ \mathrm{mm}^{3}$ ), median (range) } & $110(0-310)$ & $480(20-570)$ \\
\hline \multicolumn{3}{|c|}{ On antiretroviral therapy at start of TB episode } & $3(30 \%)$ & $6(40 \%)$ \\
\hline \multicolumn{3}{|c|}{ Diagnosed with TB during/following an inpatient admission } & $9(90 \%)$ & $9(60 \%)$ \\
\hline
\end{tabular}

TB: Tuberculosis

*Definitions of low, medium and high incidence follow British HIV Association guidance ${ }^{4}$ 
IIncludes high- or medium-TB incidence region of origin, and additional risk factors listed in the table. Several patients had more than one risk factor.

\section{"Early" TB}

Of ten patients, eight (80\%) were from medium- or high-TB incidence regions. At TB diagnosis median CD4 was 110 (range $0-310$ ) cells $/ \mathrm{mm}^{3}$. Nine (90\%) were diagnosed with TB during or following inpatient admissions. Eight (80\%), all from medium- or highincidence regions, had TB symptoms at the time of HIV diagnosis. The remaining two developed "unmasking" immune reconstitution inflammatory syndrome following ART initiation.

\section{"Late" TB}

Of 15 patients, 53\% were from high- or medium-TB incidence regions. Additionally, nine $(60 \%)$ had at least one other recognised TB risk factor, such as healthcare work or time spent in prison (Table 2). Six (40\%) were on ART at the time of TB diagnosis, for a median of 2.6 years (range 219 days-9.9 years), all virologically suppressed. Median CD4 count was 480 (range 20-570) cells $/ \mathrm{mm}^{3}$. Nine (60\%) were diagnosed during or following an inpatient admission. 14 (93\%) patients successfully completed TB therapy, but one died of disseminated TB.

\section{Missed opportunities for LTBI diagnosis and treatment}

Of the "late" TB group, 14 (93\%) met criteria for LTBI screening and treatment at some point following HIV diagnosis. The individual who did not was from a low-incidence region but did have other TB risk factors (extensive travel to high-incidence countries and previous imprisonment). Only one had LTBI screening performed. He had a negative Quantiferon Gold interferon-gamma release assay (IGRA) one month after HIV diagnosis, when his CD4 was 60 cells $/ \mathrm{mm}^{3}$; he remained at potential risk of TB exposure after screening. He was diagnosed with culture-positive pleural TB one year later.

\section{Discussion}

In our HIV service, TB continues to cause morbidity ( $72 \%$ inpatient admission rate) and occasionally mortality. Despite most patients who developed "late" TB meeting the 2011 BHIVA criteria for LTBI screening, most were not screened (in keeping with our previous audit $\left.{ }^{6}\right)$. Prompts have been included in the electronic patient record to promote LTBI screening, but our impression is that these remain underutilised. One potential barrier to clinicians initiating screening is that the 2011 BHIVA guidelines are complex, requiring integration of information about CD4, ART history and region of 
origin. The 2017 draft BHIVA guidelines recommend a simplified approach which may be easier to implement ${ }^{7}$.

Many patients, including the one who did not otherwise meet screening criteria, had additional risk factors for TB infection, suggesting that selection of patients for LTBI screening may need to take account of risk factors beyond HIV stage and region of origin. This is the approach taken by the 2017 draft guideline ${ }^{7}$.

Even with increased LTBI screening at enrolment in HIV care, it is unlikely that all "late" cases of TB were preventable. IGRA sensitivity for LTBI is not $100 \%{ }^{8}$. Furthermore, some patients developed TB many years after their HIV diagnosis, and/or had risk factors suggesting ongoing TB exposure, which may require different strategies.

Several patients had inconsistent concordance with care, and might not have taken preventative therapy even if offered; although TB preventative treatment does confer additional benefits to ART alone, optimising HIV treatment in this group might also have reduced TB incidence ${ }^{9,10,11}$. While beyond the scope of this audit, earlier HIV diagnosis might also have averted TB morbidity for the eight (32\%) patients whose TB and HIV diagnoses were essentially simultaneous (less than a two-month interval), and who all had $C D 4<350$ at diagnosis.

\section{Conclusions}

There are missed opportunities for LTBI screening in our HIV service, and improving coverage of those at highest risk could reduce morbidity and mortality. People living with HIV may benefit from an approach to LTBI screening which incorporates broader TB risk factors and ongoing TB exposure. 


\section{Funding statement}

The author(s) received no financial support for the research, authorship, and/or publication of this article.

\section{References}

1. Granich R, Akolo C, Gunneberg C, et al. Prevention of Tuberculosis in People Living with HIV. Clin Infect Dis 2010; 50: S215-S222.

2. Akolo C, Adetifa I, Shepperd S, et al. Treatment of latent tuberculosis infection in HIV infected persons. Cochrane Database Syst Rev. 20;(1):CD000171 (2010).

3. Capocci S, Smith C, Morris S, et al. Decreasing cost effectiveness of testing for latent TB in HIV in a low TB incidence area. Eur Respir J 2015; 46: 165-74.

4. Pozniak AL, Coyne KM, Miller RF, et al. British HIV Association guidelines for the treatment of TB/HIV coinfection 2011. HIV Med 2011; 12: 517-524.

5. White HA, Miller RF, Pozniak AL, et al. Latent tuberculosis infection screening and treatment in HIV: insights from evaluation of UK practice. Thorax 2017; 72: 180182.

6. Fox-Lewis A, Brima N, Muniina P, et al. Tuberculosis screening in patients with HIV: An audit against UK national guidelines to assess current practice and the effectiveness of an electronic tuberculosis-screening prompt. Int J STD AIDS 2016; 27: 901-5.

7. Pozniak AL, Bracchi M, Awosusi F, et al. British HIV Association guidelines for the management of TB/HIV co-infection in adults 2017. (Draft for consultation). Updated 2018 Jan 23. Accessed 2018 Feb 28. Available from

http://www.bhiva.org/documents/Guidelines/TB/BHIVA-TB-HIV-co-infection-guidelinesconsultation.pdf

8. Cattamanchi A, Smith R, Steingart KR, et al. Interferon-gamma release assays for the diagnosis of latent tuberculosis infection in HIV-infected individuals: a systematic review and meta-analysis. J Acquir Immune Defic Syndr 2011; 56: 230-238.9.

Rangaka MX, Wilkinson RJ, Boulle A, et al. Isoniazid plus antiretroviral therapy to prevent tuberculosis: a randomised double-blind, placebo-controlled trial. Lancet 2014; 384: 682-90.

10. Grant AD, Bansi L, Ainsworth J, et al. Tuberculosis among people with HIV infection in the United Kingdom: opportunities for prevention? AIDS 2009; 23: 25072515.

11. Gupta RK, Rice B, Brown AE, et al. Does antiretroviral therapy reduce HIVassociated tuberculosis incidence to background rates? A national observational cohort study from England, Wales, and Northern ireland. Lancet HIV 2015; 2: e243-e251. 
